\title{
Editorial: Ecological Applications of Earth System Models and Regional Climate Models
}

\author{
Rebecca G. Asch ${ }^{1 *}$, Johnna M. Holding ${ }^{2}$, Darren J. Pilcher ${ }^{3,4}$, Sara Rivero-Calle ${ }^{5}$ and \\ Kenneth A. Rose ${ }^{6}$ \\ ${ }^{1}$ Department of Biology, East Carolina University, Greenville, NC, United States, ${ }^{2}$ Department of Bioscience \& Arctic \\ Research Centre, Aarhus University, Aarhus, Denmark, ${ }^{3}$ Cooperative Institute for Climate, Ocean, and Ecosystem Studies \\ (CICOES), University of Washington, Seattle, WA, United States, ${ }^{4}$ Pacific Marine Environmental Laboratory (PMEL), National \\ Oceanic and Atmospheric Administration (NOAA), Seattle, WA, United States, ${ }^{5}$ Skidaway Institute of Oceanography, \\ University of Georgia, Athens, GA, United States, ${ }^{6}$ Horn Porn Laboratory, University of Maryland Center for Environmental \\ Science (UMCES), Cambridge, MD, United States
}

Keywords: earth system model, regional climate model, climate change, ocean acidification, marine ecosystems, biogeochemistry, fisheries

\section{Editorial on the Research Topic}

\section{OPEN ACCESS}

Edited and reviewed by: Matthias Gröger,

Leibniz Institute for Baltic Sea

Research (LG), Germany

${ }^{*}$ Correspondence: Rebecca G. Asch aschr16@ecu.edu

Specialty section:

This article was submitted to Global Change and the Future Ocean,

a section of the journal

Frontiers in Marine Science

Received: 09 September 2021 Accepted: 14 September 2021

Published: 08 October 2021

Citation:

Asch RG, Holding JM, Pilcher DJ, Rivero-Calle $S$ and Rose KA (2021) Editorial: Ecological Applications of Earth System Models and Regional

Climate Models.

Front. Mar. Sci. 8:773443.

doi: 10.3389/fmars.2021.773443

\section{Ecological Applications of Earth System Models and Regional Climate Models}

Earth system models (ESMs) that couple sub-models describing atmospheric and oceanic dynamics with models of the cryosphere and biosphere are increasingly used to project climate change. Regional climate models (RCMs) function similarly but focus on regional scales with finer resolution. Due to the inclusion of lower trophic levels in ESMs (phytoplankton, zooplankton), these models are increasingly applicable for addressing ecological questions. While ESMs and RCMs do not typically represent higher trophic levels, they provide insights through: (1) coupling with mechanistic upper trophic level models, and (2) providing outputs to parameterize statistical, habitat-based models. Both types of analyses are increasingly used to forecast the dynamics of commercially and ecologically important species for management (Payne et al., 2017; Tommasi et al., 2017; Jacox et al., 2020). There are challenges related to using ESMs to explore ecological questions due to their coarse spatial and taxonomic resolution and a lack of understanding by many ecologists of the structural differences among different ESMs (Kearney et al., 2021). This Research Topic (RT) emerged as a result of the 2014 Ecological Dissertations in Aquatic Sciences Symposium, which led to a manuscript (Asch et al., 2016) and a session at the 2019 Aquatic Sciences Meeting entitled "Ecological Applications of ESMs and RCMS." The RT includes papers from the 2019 conference session and additional contributions from the community.

\section{REGIONS}

In Figure 1, we grouped the papers in this RT based on region, trophic level, oceanic drivers of changes, and modeling approach. Five papers focused on the Northeast Pacific (California Current, Gulf of Alaska), three the Northeast Atlantic, two the Western Pacific, and three presented global analyses (Figure 1A). Studies from the southern hemisphere were underrepresented. This 
is a pattern common to meta-analyses of marine global change biology (Mackas et al., 2012; Poloczanska et al., 2013). Also not represented was the Western Atlantic; these gaps might reflect regional research priorities and the availability of welldeveloped RCMs.

\section{MODELING APPROACHES}

Contributions were evenly distributed between global ESMs and RCMs (Figure 1D). Some papers (Holdsworth et al.; Pozo Buil et al.) integrated across these models by using dynamical downscaling of global models to inform boundary conditions at the edges of RCMs. Within the ESM and RCM analyses, papers used diverse approaches to examine how physical and biogeochemical forcing impacts marine ecosystems (Figure 1E). Some studies, such as Birkmanis et al., used species distribution modeling to statistically link environmental drivers with changes in habitat suitability. Other papers used a more mechanistic approach, such as trait-based models to investigate functional group dynamics (Petrik et al.) or an individual-based approach to examine larval dispersal or animal movement (Fiechter et al.; Norton et al.). Other papers conducted model experiments where simulations of different scenarios were run to evaluate organismal responses (Bahl et al.; Bednaršek et al.). Two papers investigated coupled natural-human systems; Suh and Pomeroy used changes in fish catch to parameterize an economic model and Fiechter et al. considered fleet dynamics when modeling Pacific sardine.

Coupling ESMs and RCMs to ecological analyses offers several key advantages:

(1) Emergent properties of the coupled physical and ecological systems can be identified, revealing underlying dynamics that could be difficult to tease out via observations or experiments. For example, Bahl et al. identified biogeochemical variables that exhibit linear vs. non-linear responses to radiative forcing. Petrik et al. investigated the "pelagicification" of ocean ecosystems whereby the biomass of large pelagic fishes declines under climate change due to their increasing metabolic demands combined with decreased secondary productivity. Norton et al. followed the environmental exposure history of individual crab larvae, which would be impossible to track with solely observations.

(2) Projection of responses to future conditions (temperature, ocean acidification, hypoxia, stratification) are well-grounded by the use of ESMs and RCMs. Such analyses also allow the separation of effects due to individual stressors that often co-occur. Bednaršek et al. differentiated between changes in aragonite saturation due to rising $\mathrm{CO}_{2}$ and eutrophication by using model scenarios to separate these effects. Boyd et al. differentiated between multiple drivers affecting Atlantic mackerel and concluded that fishing mortality had a larger effect than climate change.

(3) Model simulations can identify rapidly changing locations or organisms at risk. Reygondeau et al. identified no-analog biogeochemical provinces that emerged under climate change. How organisms will adapt and acclimate to these novel conditions is unknown and modeling results could help ensure ecological monitoring is in place to detect such responses.

\section{INTEGRATING OCEAN OBSERVATIONS AND MODELS}

In situ observations are often the most reliable measure of a variable. However, they can be costly to obtain and may lack resolution in space or time. Satellite products are useful for increasing coverage, but rely on calibration with in situ measurements (Behrenfeld and Falkowski, 1997). Although using satellite data requires additional training, integrating in situ and satellite approaches with modeling is a logical step forward and is illustrated with two papers on the North Sea. This focus on the North Sea may reflect its historical wealth of observations and heterogeneous oceanography, which is difficult for models to capture. North Sea mixing is controlled by tidal influence along the coast and convective forcing offshore, both of which affect biogeochemistry and phytoplankton biomass. Mészáros et al. integrated satellite, in situ, and model observations to describe more accurately the dynamic nature of the region and project changes in primary productivity. Biogeochemistry of the coastal North Sea is also highly influenced by terrestrial run-off. Xu et al. showed coastal and offshore sites had different historical trends in chlorophyll $a$, with decreasing concentrations offshore and increasing trends along the coast despite a decrease in nutrient supply. This result was counterintuitive, leading them to conclude that satellite and modeling data should be used together to reassess in situ monitoring locations.

\section{SPECIES AND CLIMATE DRIVERS}

Climate change is a multifaceted phenomenon that causes changes in diverse physico-chemical ocean characteristics. Papers covered a wide range of oceanic drivers affected by climate change that impact marine ecosystems (Figure 1C). The most common drivers examined were changes in temperature and primary and secondary productivity. Notably missing were studies examining sea level rise, which has a substantial effect on habitat availability and coastal ecosystem functioning (Oppenheimer et al., 2019). This gap likely reflects that ESMs and RCMs operate at broader geographic scales than most analyses of sea level rise that focus on nearshore environments.

Papers were nearly evenly distributed among examining nutrients and biogeochemical dynamics, primary production, and upper trophic levels (Figure 1B). Several papers also investigated the dynamics of zooplankton, benthos, and fisheries. The few examples focused on zooplankton may reflect that they tend to be poorly represented in both nutrient-phytoplanktonzooplankton-detritus models and upper trophic level models (Rose et al., 2010).

Six papers projected the responses of fish and crabs to future climate (Figure 1B). Use of Representative Concentration Pathway 8.5 was common across all analyses; several studies also included other Representative Concentration Pathways. These papers showed that the response of upper trophic levels to future 


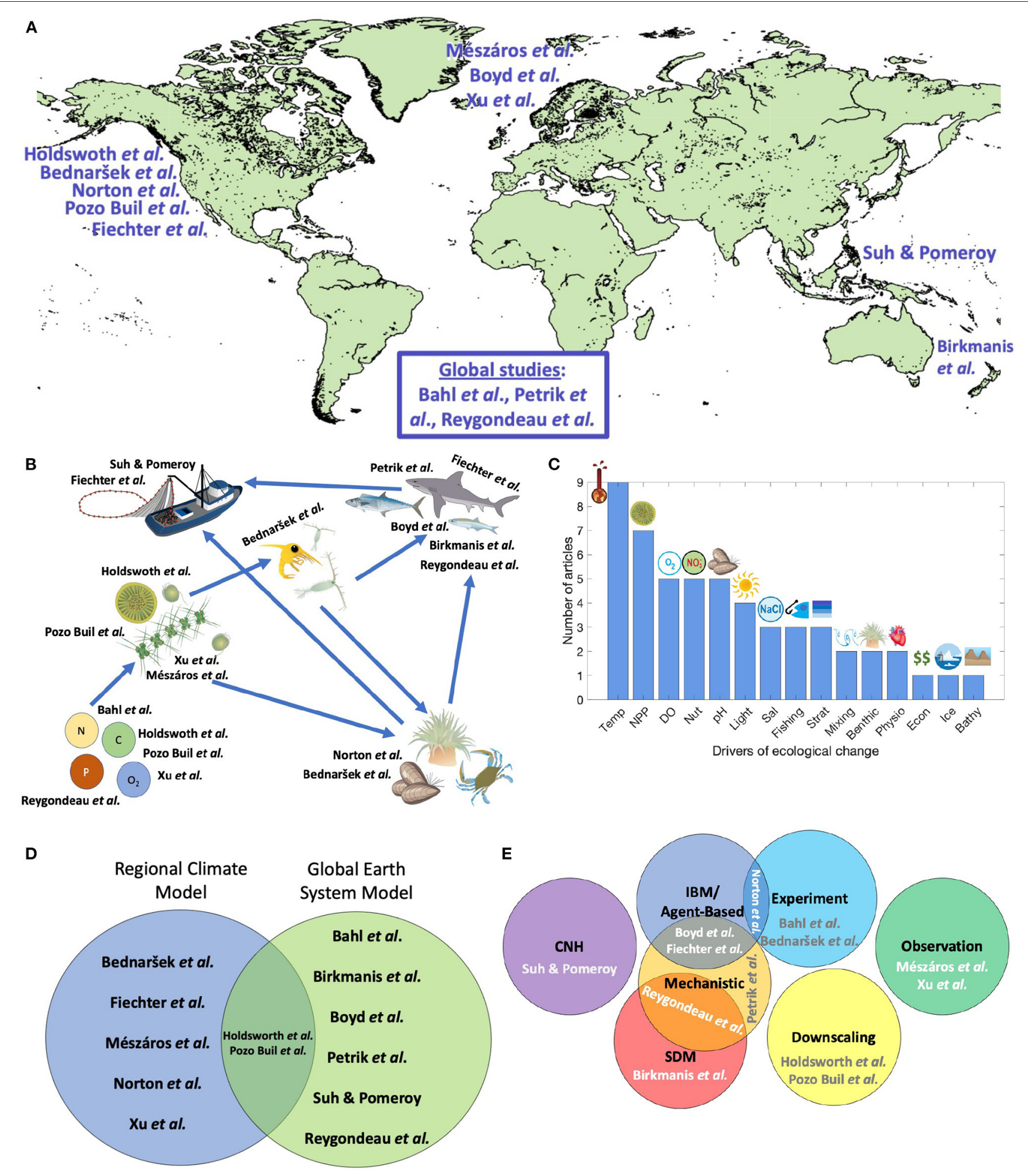

FIGURE 1 | Shared characteristics of papers in this Research Topic (RT). (A) Geographic distribution of studies. (B) Trophic level examined. This diagram contains pictorial representations of nutrients, primary producers, zooplankton, benthic organisms, top predators, and fisheries. Arrows depict flows between these trophic levels. If a study considered primary production mainly as a driver of ecological change at higher trophic levels, then this study is represented in this diagram as focusing on higher trophic levels rather than primary producers. (C) Drivers of ecological change examined in this RT. Temp, temperature; NPP, net primary production. (Continued) 
FIGURE 1 | This also includes studies examining chlorophyll concentration or secondary production; DO, dissolved oxygen; Nut, nutrients; pH, includes all studies examining ocean acidification and the carbonate chemistry system; Light, includes studies examining changes in turbidity or euphotic depth; Sal, salinity; Strat, stratification. This includes studies examining changes in mixed layer depth (MLD) since MLD is often measured as a function of stratification; Mixing, includes upwelling and mixing by eddies; Physio, includes physiological and metabolic rates; Econ, economic drivers; Bathy, bathymetry. If phytoplankton dynamics are examined by a study as the primary ecological variable of interest, then primary producers are classified as a response variable and not the underlying driver of change. (D) Venn diagram indicating how many studies utilized regional climate models (RCMs) and global earth system models (ESMs). The intersection between these categories includes dynamical downscaling studies that used outputs from ESMs to simulate future changes in regional climate. Studies that utilized RCMs but where downscaling was not a major focus of the manuscript were placed solely in the RCM category. (E) Venn diagram of modeling and observational approaches used in each manuscript. SDM, species distribution model; IBM, individual-based model; CNH, coupled natural-human system. Mechanistic models refer to the ecological component of the model and not the underlying ESM or RCM. Classifications are based on a study's primary modeling approach. Illustrations are from ian.umces.edu/media-library and freepik.com.

climate was not a simple decline or poleward shift following optimal temperatures. Projected responses were complicated, including positive and negative responses in abundance that were accompanied by changes in the location and shape of spatial distributions. For example, Petrik et al. predicted general declines in their fish functional groups within an ESM under climate change but groups differed in how closely they tracked the climate-induced changes in productivity and their prey. Birkmanis et al. predicted opposite responses of two different shark species, while Boyd et al. and Fiechter et al. predicted long-term increases in their study species.

Overall, RT papers were diverse in terms of modeling approach, focal ecosystems, and species examined. The research approaches described provide examples of how ESMs and RCMs can be coupled to models to address ecological questions related to climate change. Some missing topics include paleo-ecological studies, data assimilation, integration of data from autonomous observational platforms (Chai et al., 2020), and examination of climate variability. The recent publication of the 6th Assessment Report by the Intergovernmental Panel on Climate Change will provide additional impetus to continue the application of ESMs and RCMs to answer pressing ecological questions.

\section{AUTHOR CONTRIBUTIONS}

All authors contributed to writing and editing this editorial. Figure 1 was prepared by RGA.

\section{REFERENCES}

Asch, R. G., Pilcher, D. J., Rivero-Calle, S., and Holding, J. (2016). Demystifying models: answers to ten common questions that ecologists have about earth system models. Limnol. Oceanogr. Bull. 25, 65-67. doi: 10.1002/lob. 10113

Behrenfeld, M. J., and Falkowski, P. G. (1997). Photosynthetic rates derived from satellite-based chlorophyll concentration. Limnol. Oceanogr. 42, 1-20. doi: 10.4319/lo.1997.42.1.0001

Chai, F., Johnson, K. S., Claustre, H., Xing, X., Wang, Y., Boss, E., et al. (2020). Monitoring ocean biogeochemistry with autonomous platforms. Nat. Rev. Earth Env. 1, 315-326. doi: 10.1038/s43017-020-0053-y

Jacox, M. G., Alexander, M. A., Siedlecki, S., Chen, K., Kwon, Y. O., Brodie, S., et al. (2020). Seasonal-to-interannual prediction of North American coastal marine ecosystems: forecast methods, mechanisms of predictability, and priority developments. Prog. Oceanogr. 183:102307. doi: 10.1016/j.pocean.2020.1 02307

\section{FUNDING}

RGA was supported by the East Carolina University Department of Biology and an Alfred P. Sloan Foundation Research Fellowship. SR-C was supported by the University of Georgia Skidaway Institute of Oceanography. JH was supported by European Commission H2020 project INTAROS (Grant No. 727890). DP was supported by the Cooperative Institute for Climate, Ocean, and Ecosystem Studies (CICOES) under NOAA Cooperative Agreement NA20OAR4320271. This is CICOES contribution \#2021-1160, PMEL contribution \#5308, and EcoFOCI-1017.

\section{ACKNOWLEDGMENTS}

We would like to acknowledge the organizers of the 2014 Ecological Dissertations in Aquatic Sciences Symposium since this RT is a product of dialogues initiated at that symposium. Symposium sponsors include the Association for the Sciences of Limnology and Oceanography, the University of Hawaii at Manoa, and the Center for Microbial Oceanography: Research and Education. Several of the papers included here were originally presented at the 2019 Aquatic Science Meeting in San Juan, Puerto Rico, which was also sponsored by the Association for the Sciences of Limnology and Oceanography. Lastly, we thank all contributors to this RT.

Kearney, K. A., Bograd, S. J., Drenkard, E., Gomez, F. A., Haltuch, M., Hermann, A. J., et al. (2021). Using global-scale earth system models for regional fisheries applications. Front. Mar. Sci. 8:622206. doi: 10.3389/fmars.2021.622206

Mackas, D. L., Greve, W., Edwards, M., Chiba, S., Tadokoro, K., Eloire, D., et al. (2012). Changing zooplankton seasonality in a changing ocean: comparing time series of zooplankton phenology. Prog. Oceanogr. 97-100, 31-62. doi: 10.1016/j.pocean.2011.11.005

Oppenheimer, M., Glavovic, B. C., Hinkel, J., van de Wal, R., Magnan, A. K., AbdElgawad, A., et al. (2019). "Sea level rise and implications for low-lying islands, coasts and communities," in IPCC Special Report on the Ocean and Cryosphere in a Changing Climate, eds H. O. Pörtner, D. C. Roberts, V. Masson-Delmotte, P. Zhai, M. Tignor, E. Poloczanska, et al. (Cambridge: Cambridge University Press), 321-445.

Payne, M. R., Hobday, A. J., MacKenzie, B. R., Tommasi, D., Dempsey, D. P., Fässler, S. M. M., et al. (2017). Lessons from the first generation of marine ecological forecast products. Front. Mar. Sci. 4:289. doi: $10.3389 /$ fmars.2017.00289 
Poloczanska, E. S., Brown, C. J., Sydeman, W. J., Kiessling, W., Schoeman, D. S., Moore, P. J., et al. (2013). Global imprint of climate change on marine life. Nat. Clim. Change 3, 919-925. doi: 10.1038/nclimate1958

Rose, K. A., Allen, J. I., Artioli, Y., Barange, M., Blackford, J., Carlotti, F., et al. (2010). End-to-end models for the analysis of marine ecosystems: challenges, issues, and next steps. Mar. Coast. Fish. 2, 115-130. doi: 10.1577/C09-059.1

Tommasi, D., Stock, C. A., Hobday, A. J., Methot, R., Kaplan, I. C., Eveson, P. J., et al. (2017). Managing living marine resources in a dynamic environment: the role of seasonal to decadal climate forecasts. Prog. Oceanogr. 152, 15-49. doi: 10.1016/j.pocean.2016.12.011

Conflict of Interest: The authors declare that the research was conducted in the absence of any commercial or financial relationships that could be construed as a potential conflict of interest.
Publisher's Note: All claims expressed in this article are solely those of the authors and do not necessarily represent those of their affiliated organizations, or those of the publisher, the editors and the reviewers. Any product that may be evaluated in this article, or claim that may be made by its manufacturer, is not guaranteed or endorsed by the publisher.

Copyright $\odot 2021$ Asch, Holding, Pilcher, Rivero-Calle and Rose. This is an openaccess article distributed under the terms of the Creative Commons Attribution License (CC BY). The use, distribution or reproduction in other forums is permitted, provided the original author(s) and the copyright owner(s) are credited and that the original publication in this journal is cited, in accordance with accepted academic practice. No use, distribution or reproduction is permitted which does not comply with these terms. 